\title{
PHOTOINDUCED DEFECTS CREATION ON SULFUR PASSIVATED SURFACE OF GaAs*
}

\author{
Z.R. ŻYTKIEWICZ ${ }^{a, b}$, L. DoBACZEWSKI ${ }^{b}$, D. GoMEZ ${ }^{a}$ AND F. BRIONES ${ }^{a}$ \\ ${ }^{a}$ Instituto de Microelectronica de Madrid \\ Isaac Newton 8, 28760 Tres Cantos, Madrid, Spain \\ ${ }^{b}$ Institute of Physics, Polish Academy of Sciences \\ Al. Lotników 32/46, 02-668 Warsaw, Poland
}

We report on photoinduced defect creation on the sulfurized (100) GaAs surface. The process manifests itself by unrecoverable temporal decrease in the photoluminescence intensity of the GaAs surface treated by $\left(\mathrm{NH}_{4}\right)_{2} \mathrm{~S}_{x}$ solution. The results are discussed in terms of a photoind uced process of the As $\mathrm{Ga}_{\mathrm{a}}$ antisite generation on the sulfurized surface of GaAs.

PACS numbers: 68.35.Dv, 68.45.Da

\section{Introduction}

Large surface recombination velocity $\left(\approx 10^{7} \mathrm{~cm} / \mathrm{s}\right)$ for GaAs causes severe problems in possible applications of this material. As a promising solution to a problem of the GaAs surface passivation, a sulfidation has gained a lot of attention recently due to its beneficial effects on semiconductor surface electronic properties. It is known that the GaAs sulfidation treatment can reduce the surface recombination velocity and improve a performance of minority carrier devices like heterostructure bipolar transistors. Moreover, such treatments have been shown to be effective in a photoluminescence (PL) intensity enhancement, increase in Schottky barrier height dependence on the metal work function, and improvement in $C-V$ characteristics of MIS structures. Such a behavior is explained by an ability of sulfidation treatments to remove a superficial native oxide and to saturate bonds on a fresh crystal face by sulfur atoms. These atoms protect the surface against further oxidation. In this work we report on a PL intensity degradation which indicates a photoinduced defect creation on the sulfidized GaAs surface.

\section{Experimental}

The samples studied were silicon doped (100) GaAs wafers ( $n=$ $2 \times 10^{17} \mathrm{~cm}^{-3}$ ). They were prepared by etching in $3 \mathrm{H}_{2} \mathrm{SO}_{4}+1 \mathrm{H}_{2} \mathrm{O}_{2}+1 \mathrm{H}_{2} \mathrm{O}$ (samples $A$ ) followed by soaking in $\left(\mathrm{NH}_{4}\right)_{2} \mathrm{~S}_{x}$ solution (containing $8 \%$ of excess sulfur)

*This work is supported in part by the Committee for Scientific Research (Poland) grant No. 8 T11B 03010 and by Ministry of Education of Spain. 
at $50^{\circ} \mathrm{C}$ for 1 hour. Then, the wafers were rinsed with deionized water (samples $B$ ) or dried under a stream of nitrogen (samples $C$ ) and loaded to a cryostat for PL measurements at room temperature. The cryostat was continuously pumped to keep inside $10^{-3}-10^{-4}$ mbar vacuum. Ar laser with the beam power density of $8 \mathrm{~W} / \mathrm{cm}^{2}$ was used as an excitation source.

\section{Results and discussion}

Figure 1 shows temporal behavior of the room temperature PL intensity measured at $\lambda=866 \mathrm{~nm}$ for the samples $A, B$ and $C$. The PL intensities are normalized to the intensity from an untreated (as from the box) reference GaAs wafer. As shown in Fig. 1a, the procedure $C$ results in an enhancement of the band-to-band PL signal by a factor of 3. However, during 10-20 minutes after sample illumination it decreases to the level observed on untreated wafer. A simple covering of the sample by nontransparent material showed that the PL intensity loss was not due to a local heating or charging of the sample. The high luminescence intensity could be recovered only by shining the exciting light on a new point of the same sample. After that, the PL decay used to appear. The decay time of the PL signal was observed to be shorter for larger laser beam power densities.
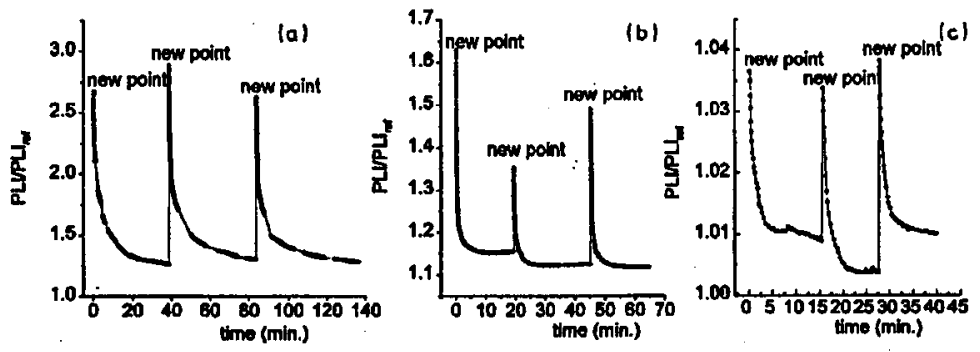

Fig. 1. Temporal behavior of the room temperature PL intensity at $\lambda=866 \mathrm{~nm}$ of (a) S-passivated and $\mathrm{N}_{2}$ dried, (b) S-passivated and water rinsed, (c) freshly ctched GaAs. The high PL intensity can be recovered by moving of the beam to a new point on the same sample.

The same temporal behavior of the luminescence intensity was observed for sulfur passivated and water rinsed wafers (samples $B$, Fig. 1b) as well as for freshly etched GaAs (samples $A$, Fig. 1c). In that case, however, the initial PL intensity was lower than for the sample $C$. The similar behavior of $\mathrm{PL}$ for $\left(\mathrm{NH}_{4}\right)_{2} \mathrm{~S}_{x}$-treated, metalorganic chemical vapor deposition (MOCVD) grown AlGaAs epitaxial layers was also observed. Moreover, when the sample $C$ was studied again after 4 months storage in air the initial PL intensity was still 1.5 times larger than that of the reference wafer.

The obtained results show that the GaAs surfaces treated by $\left(\mathrm{NH}_{4}\right)_{2} \mathrm{~S}_{x}$ are unstable under laser beam illumination. Moreover, the PL intensity loss is localized and irreversible, which indicates a permanent modification of the GaAs surface by the laser beam. 


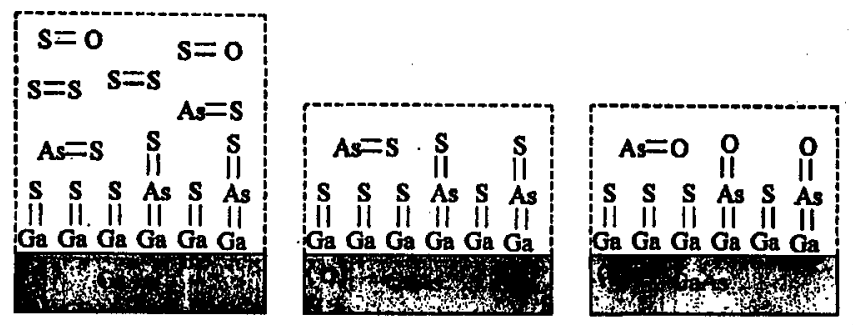

Fig. 2. Schematical presentation of GaAs surface composition after passivation (a) followed by water rinse or vacuum treatment at room temperature (b) and exposure to the air and light (c).

In order to explain these facts let us recall some published results on the chemistry and structure of sulfidized GaAs surface. Photoemission spectroscopy of $\left(\mathrm{NH}_{4}\right)_{2} \mathrm{~S}_{x}$ treated surfaces revealed the existence of the As-S, Ga-S and S-S bonds [1]. Nowadays, there is a common opinion that the passivation removes the native oxide leaving the surface with a layer of sulfur bonded to $\mathrm{Ga}$ and As. Next, the surface is covered by a thick robust layer of As sulfide and elemental sulfur (see Fig. 2a). Nannichi et al. [2] claims that this overlayer can be removed by keeping the surface in a vacuum for $30 \mathrm{~min}$ at room temperature (as we did with samples $C$ ) or by rinsing it with water (samples $B$ ); both procedures result in the monoatomic layer of sulfur left on the surface. However, a more recent paper by Paget et al. [3] shows that the overlayer does not disappear completely by sublimation in vacuum at room temperature and the heat treatment is necessary to remove all residual As sulfide from the surface. Therefore, some residual As sulfide is shown in Fig. 2b. When the excess sulfur is removed, oxygen in the cryostat can easily stick directly to the GaAs surface. Oxidation of GaAs by the $\mathrm{Ga}-\mathrm{S}$ bond dissociation is unlikely, because of a high energy of this bond $(\approx 5.7 \mathrm{eV}$ on $(001)$ surface of GaAs [4]). However, it is expected that the As-S bond is much weaker. In fact, Sandroff et al. [5] reports decomposition of surface $\mathrm{As}_{x} \mathrm{~S}_{y}$ phases into $\mathrm{As}_{2} \mathrm{O}_{3}$ and $\mathrm{SO}_{2}$ (volatile gas product) in the presence of oxygen and white light. Moreover, it is known that in the solid-state part of the $\mathrm{Ga}-\mathrm{As}-\mathrm{S}-\mathrm{O}$ quaternary equilibrium phase diagram $\mathrm{GaS}, \mathrm{Ga}_{2} \mathrm{O}_{3}$ and $\mathrm{As}$ are the most stable phases [6]. As a result, $\mathrm{As}_{2} \mathrm{O}_{3}$ should react via the following chemical reaction:

$$
2 \mathrm{GaAs}+\mathrm{As}_{2} \mathrm{O}_{3} \rightarrow \mathrm{Ga}_{2} \mathrm{O}_{3}+4 \mathrm{As}
$$

forming on the surface stable gallium oxide and free As. Areas of the surface, where the $\mathrm{Ga}-\mathrm{S}$ bonds dominate remain unchanged. However, a possibility exists that in such places oxygen can diffuse underneath the $\mathrm{Ga}-\mathrm{S}$ layer oxidizing $\mathrm{GaAs}$ and leaving the $\mathrm{Ga}-\mathrm{S}$ layer unoxidized [7]. It has been suggested [8] that during oxygen adsorption on a clean GaAs surface energy released is large enough to create surface defects. In our case this may happen when the excess As produced as a result of the reaction (1) may become the $\mathrm{As}_{\mathrm{Ga}}$ antisite defect responsible for the surface Fermi level pinning and the PL degradation. In fact, the valence band bending is of $0.6-0.7 \mathrm{eV}$ when measured on the sulfidized GaAs surface exposed to 
air [7]. This is close to the value of $0.65 \mathrm{eV}$ for the $\mathrm{As}_{\mathrm{Ga}}$ antisite defect predicted by the advanced unified defect model [9].

According to this simple model of surface reactions, the following explanation of the results shown in Fig. 1 can be suggested. First, let us point out that the sulfurized GaAs surfaces exhibit significantly higher PL intensity than the untreated ones. This indicates a serious reduction of the surface defects density caused by the passivation. The amorphous sulfur overlayer covering the surface plays an important role in protection of the surface against oxidation. When this overlayer is removed by rinsing the surface with water before transfer of the sample to the cryostat (samples $B$ ) the surface gets partly oxidized. On contrary, when the protective layer is removed by sulfur sublimation under vacuum (samples $C$ ) a lower degree of the surface degradation and the higher PL intensity is observed. Next, oxygen is continuously covering the surface inside the cryostat. It has been already reported that this leads to the decay of the PL intensity from sulfurized GaAs [7, 10]. Up till now however, a general view is that the whole area of the sample is degraded simultaneously and the role of the laser beam is only to probe the state of the surface. The data shown in Fig. 1 evidence the photoinduced character of the surface degradation process. We expect that oxygen is weakly bonded to the surface and the degradation of passivated GaAs occurs (e.g. by the $\mathrm{As}_{\mathrm{Ga}}$ defects creation via the reaction (1)) at the point excited by the laser beam. We believe that this is the only way to explain the visible in Fig. 1 recovery of high PL intensity when a new point of the sample is illuminated. This also explains why the efficient PL can be observed on samples stored for 4 months in air without intensive illumination.

\section{References}

[1] J.T. Hsieh, H.L. Hwang, Appl. Surf. Sci. 92, 222 (1996).

[2] Y. Nannichi, J.-F. Fan, H. Oigawa, A. Koma, Jpn. J. Appl. Phys. 27, L2367 (1988).

[3] D. Paget, V.L. Berkovits, A.O. Gusev, J. Vac. Sci. Technol. A 13, 2368 (1995).

[4] T. Ohno, Phys. Rev. B 44, 6306.(1991).

[5] C.J. Sandroff, M.S. Hedge, C.C. Chang, J. Vac. Sci. Technol. B 7, 841 (1989).

[6] Yu.V. Medvedev, Appl. Phys. Lett. 69, 3458 (1994).

[7] M. Oshima, T. Scimeca, Y. Watanabe, H. Oigawa, Y. Nannichi, Jpn. J. Appl. Phys. 32, 518 (1993).

[8] W.E. Spicer, P.W. Chye, P.R. Skeath, C.Y. Su, I. Lindau, J. Vac. Sci. Technol. 16, 1422 (1979).

[9] W.E. Spicer, Z. Liliental-Weber, E. Weber, N. Newman, T. Kendelewicz, R. Cao, C. McCants, P. Mahowald, K. Miyao, I. Lindau, J. Vac. Sci. Technol. B 6, 1245 (1988).

[10] Z.S. Li, W.Z. Cai, R.Z. Su, G.S. Dong, D.M. Huang, X.M. Ding, X.Y. Hou, X. Wang, Appl. Phys. Lett. 64, 4325 (1994). 